\title{
DUNAS MÓVEIS: ÁREAS DE PRESERVAÇÃO PERMANENTE?
}

\section{Dunes mobile: Permanent Preservation Areas?}

\author{
Mônica Virna Aguiar Pinheiro \\ Doutoranda em Ciências Marinhas Tropicais \\ Universidade Federal do Ceará, Fortaleza, Ceará, Brasil \\ monivirna@yahoo.com.br \\ Marcelo Martins Moura-Fé \\ mourafe.marcelo@yahoo.com.br \\ Eduardo Marcelo Negreiros Freitas \\ eduardomnfreitas@hotmail.com \\ Anatarino Torres Costa \\ anatarino@yahoo.com.br \\ Aline Carla Sousa Aguiar \\ alineaguiar07@gmail.com \\ Enio Tarsom Paiva Sombra \\ eniotarsom@gmail.com
}

Artigo recebido em 27/02/2013 e aceito para publicação em 27/06/2013

RESUMO: O Artigo trata sobre a pertinência das Dunas Móveis enquanto áreas de preservação permanente (APP), apesar dessa condição não estar inserida na Lei Federal $n^{\circ} 12.651 / 2012$, recentemente promulgada e que trata do Novo Código Florestal. Embora se tratar de ambiente de importância natural, geológica, geográfica, biológica, ecológica e paisagística, dentre outros aspectos, atualmente se observa uma lacuna legal no Estado do Ceará que trate de forma específica e clara da proteção dessa significativa feição natural presente em diversos setores do litoral cearense. São apresentados e discutidos os principais diplomas sobre esse tema na legislação ambiental brasileira. Metodologicamente foi realizada uma detalhada análise dos diplomas legais, além do levantamento bibliográfico acerca de análises sobre essa discussão, além da caracterização ambiental das dunas móveis. O artigo apresenta como principais objetivos, a apresentação e análise dos meios legais para que essa condição de inseguridade legal seja revertida. Como principais resultados o artigo apresentada os meios legais, bem como a ampla justificativa científica e técnica embasada na importância ambiental das dunas, para que as mesmas possam estar inseridas no contexto do Meio Ambiente legalmente protegido, sob a pena de vermos a ocupação e descaracterização desse patrimônio natural irremediavelmente estabelecidos.

Palavras-Chave: Dunas Móveis, Áreas de Preservação Permanente, Legislação Ambiental, Meio Ambiente, Estado do Ceará. 
Dunas móveis: Áreas de Preservação Permanente?

Mônica Virna Aguiar Pinheiro, Marcelo Martins Moura-Fé, Eduardo Marcelo Negreiros Freitas, Anatarino Torres Costa,

Aline Carla Sousa Aguiar, Enio Tarsom Paiva Sombra

ABSTRACT: The article deals with the relevance of the Dunes Mobile as permanent preservation areas (APP), despite this condition not be inserted in the Federal Law N ${ }^{\circ} .12 .651 / 2012$, recently enacted and that is the New Forest Code. Despite its importance natural, geological, geographical, biological, ecological and landscape, among other things, now we can see a loophole in the state of Ceará that addresses a specific and clear protection of this significant natural feature present in many sectors of Ceará. Are presented and discussed key pieces on this theme in Brazilian environmental legislation. Methodologically were made a detailed analysis of the legislation on the subject, besides the literature concerning the analysis of this discussion, in addition to environmental characterization of the dunes. The paper presents the main objectives, the presentation and analysis of legal means for this condition of insecurity cool is reversed. As the article main results presented legal means as well as ample justification grounded in scientific and technical environmental importance of the dunes, so that they can be placed in context of the Environment legally protected under the penalty of seeing the occupation and this mischaracterization natural heritage irrevocably established.

Key Words: Dunes Mobile, Permanent Preservation Areas, Environmental Law, Environment, State of Ceara.

\section{INTRODUÇÃO}

O litoral brasileiro abrange diversos ecossistemas e dentre estes, encontram-se os campos de dunas móveis, os quais podem ser verificados nas mais diversas formas, extensões e caracterizações espaciais. $\mathrm{O}$ ambiente de dunas pode ser encontrado desde o litoral do Estado do Rio Grande do Sul (região sul do país) ao Estado do Amazonas (região norte brasileira). Contudo, mesmo ocorrendo em quase todo o litoral brasileiro, seu predomínio se dá de forma mais enfática ao longo da zona litorânea do nordeste brasileiro, com as maiores exposições ocorrendo entre os Estados do Rio Grande do Norte e do Maranhão, passando, por conseguinte, no contexto territorial do Estado do Ceará.

Os corpos dunares ao se formarem, ganham contornos distintos, os quais se definem através de diferenciações estreitamente relacionadas à direção do vento dominante, à conformação da superfície percorrida pelos sedimentos desde sua disponibilização, à ação dos ventos na faixa de praia e à localização dessas dunas dentro do segmento costeiro (PINHEIRO, 2009).

As grandes famílias de formas dunares caracterizam-se quanto à sua morfologia em: dunas móveis, dunas semifixas, dunas fixas, os eolianitos (ou dunas cimentadas) e as formas de deflação. Especificamente, as dunas móveis caracterizam-se por um transporte permanente dos grãos de areia, resultando em uma permanente migração das formas dunares.

As dunas móveis são formadas a partir da acumulação de sedimentos, sobremaneira grãos de areia, os quais são removidos da face de praia e depositados costa adentro por conta da ação dos agentes eólicos (ventos predominantes). Além disso, vale informar que as dunas móveis caracterizam-se pela ausência de vegetação ou pela fixação de um revestimento pioneiro (Figuras 01 e 02), o qual detém ou atenua os efeitos da dinâmica eólica, responsável pela migração (PINHEIRO, 2009; MOURA-FÉ, 2008). 
Figura 1. Dunas Móveis verificadas no Parque Nacional de Jericoacoara, Município de Jijoca de Jericoacoara, litoral oeste do Estado do Ceará

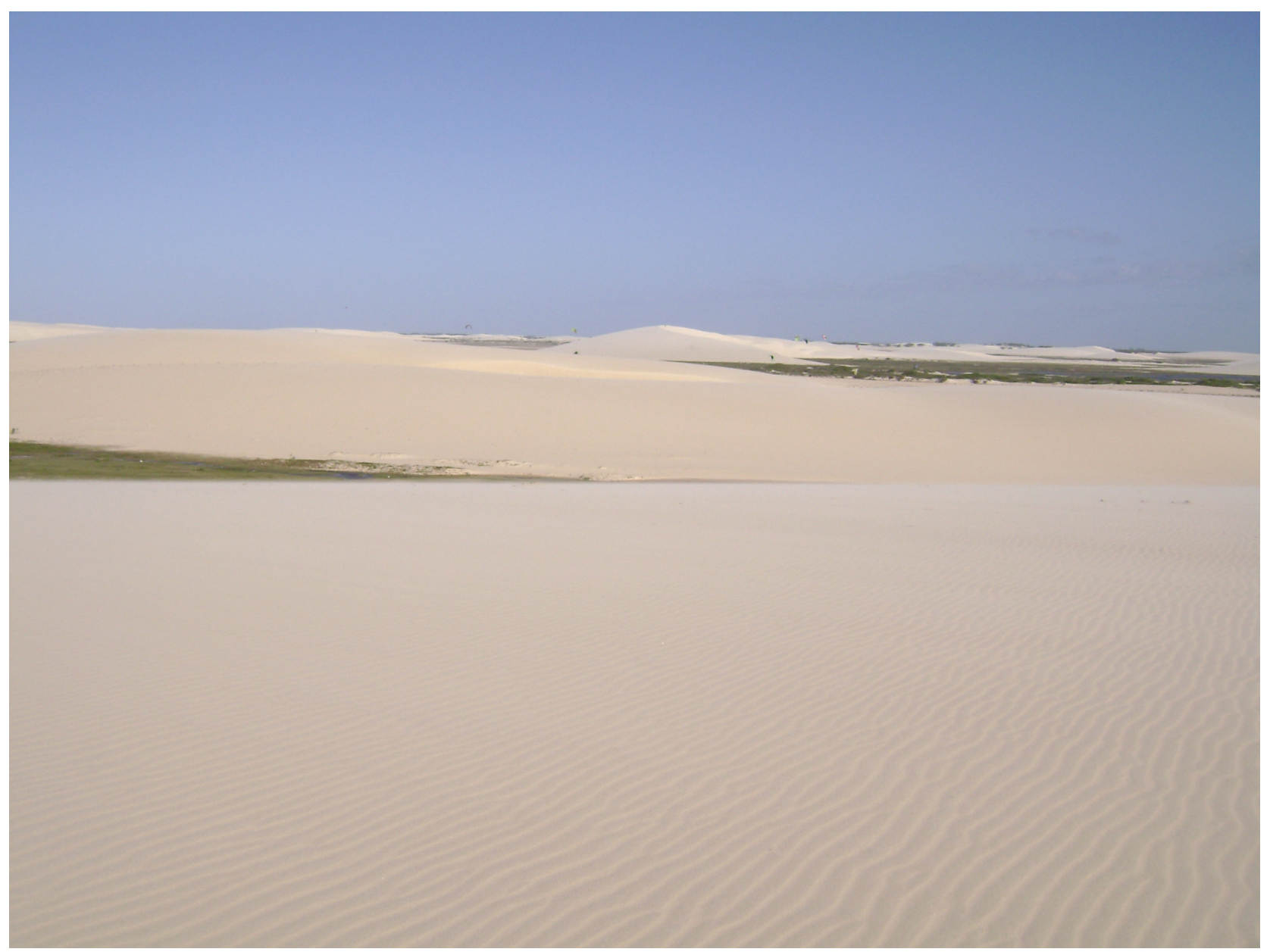

Foto: Marcelo Martins (agosto de 2009).

Por sua vez, as dunas chamadas semi-fixas caracterizam-se pela semi-mobilidade, ou seja, não são totalmente móveis e nem totalmente fixas. Sua característica principal é possuir partes de sua estrutura coberta pela vegetação, demonstrando que há aporte mais ou menos equilibrado com a saída de sedimentos, de forma a haver mobilidade (dos sedimentos), mas não migração (mudança espacial) do corpo dunar. Isto é, o saldo entre entrada (input) e saída (output) de sedimentos é praticamente zero (PINHEIRO, 2009). 
Dunas móveis: Áreas de Preservação Permanente?

Mônica Virna Aguiar Pinheiro, Marcelo Martins Moura-Fé, Eduardo Marcelo Negreiros Freitas, Anatarino Torres Costa, Aline Carla Sousa Aguiar, Enio Tarsom Paiva Sombra

Figura 2. Dunas Móveis na Praia da Baleia, Município de Itapipoca, litoral oeste do Estado do Ceará

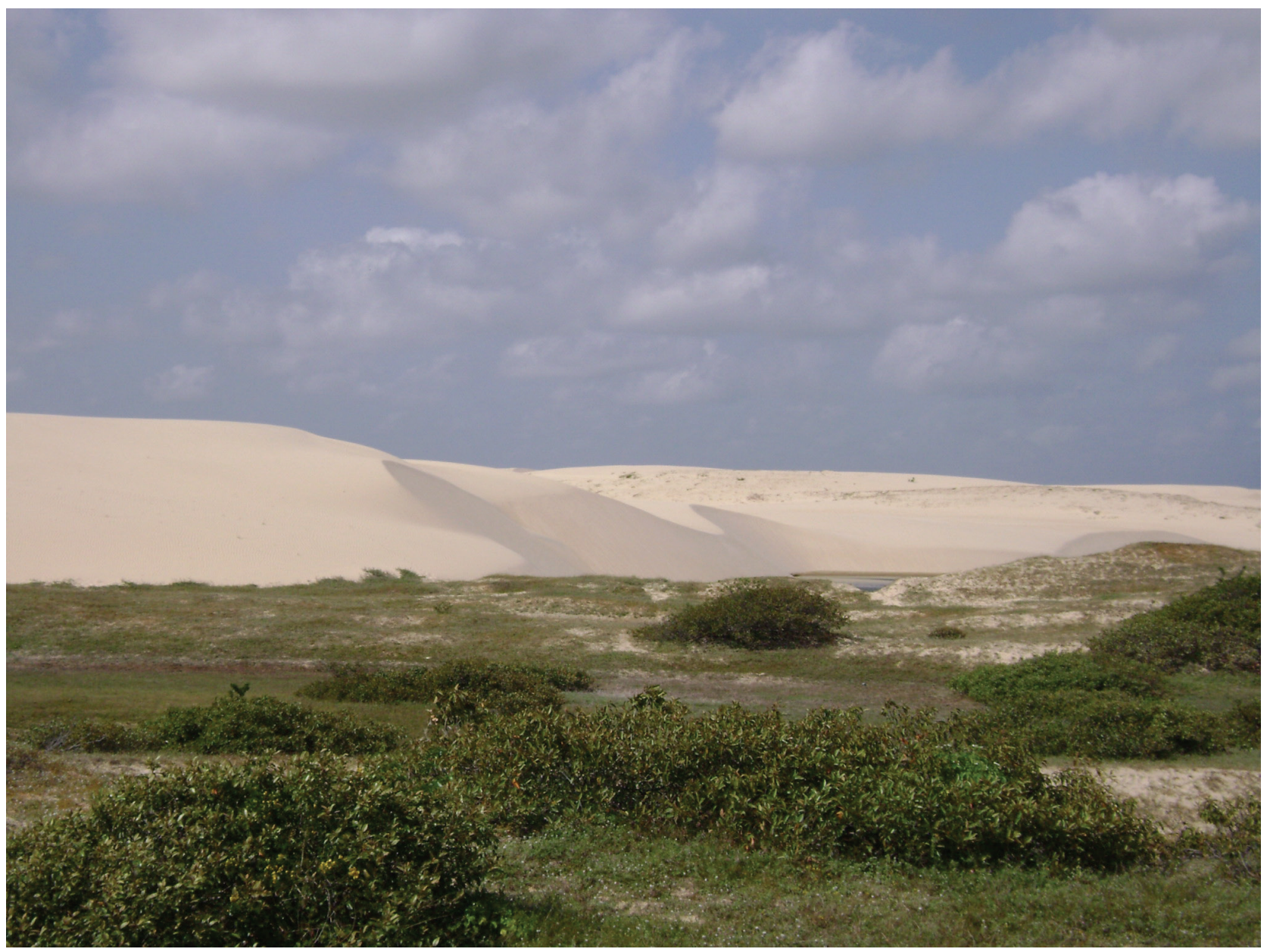

Foto: Marcelo Martins (agosto de 2009).

Segundo Pinheiro (2009), em relação à morfologia das dunas, por fim, no tocante às dunas fixas, essas feições são caracterizadas pela imobilidade atual dos sedimentos que as compõem, a partir da colonização por vegetação costeira, a qual, por sua vez, pode alcançar até um porte arbóreo.

De maneira geral, pode-se dizer que todas as dunas costeiras estabilizadas atualmente indicam terem tido algum tipo de mobilidade no passado, provavelmente sob regime climático diferente do atual (TSOAR; ARENS, 2003).

Ainda de acordo com Pinheiro (2009), as dunas, sejam elas móveis ou fixas, se comportam como ambientes propícios ao acúmulo de águas pluviais, alimentando um dos principais aqǘferos dentro do ambiente de zona costeira, corroborando sua importância hidro-geológica.

Essa característica torna-se ainda mais relevante ao considerarmos ambientes com tendência à semi-aridez (como zonas costeiras) ou em franco quadro climático de semi-aridez, como é o caso do Nordeste brasileiro, de constituição litológica essencialmente cristalina, portanto, pobre quanto à disponibilidade de águas superficiais (decorrente dos elevados índices de evaporação e evapotranspiração) e subterrâneas (derivada das características cristalinas do substrato geológico presentes na maior parte do território cearense) (PINHEIRO, 2009).

Os campos de dunas têm ainda uma importância fundamental no equilíbrio das zonas costeiras, ao fornecer sedimentos para rios e/ou praias, alimentando assim, direta ou indiretamente, a deriva litorânea presente ao longo da costa cearense, direcionada, grosso modo, no sentido: leste-oeste, que por sua vez, alimenta de sedimentos as praias. Assim, em seu processo de migração ao longo da costa, as dunas controlam e regulam o balanço sedimentar de todo o ambiente costeiro (PINHEIRO, 2009). 
Dunas móveis: Áreas de Preservação Permanente? Mônica Virna Aguiar Pinheiro, Marcelo Martins Moura-Fé, Eduardo Marcelo Negreiros Freitas, Anatarino Torres Costa, Aline Carla Sousa Aguiar, Enio Tarsom Paiva Sombra

Por serem formações de acúmulos de sedimentos, as dunas tornam-se imprescindíveis na manutenção direta das faixas de praias, através do fornecimento contínuo de grãos, diminuindo, assim, a possibilidade de erosão destas. Em alguns locais, as dunas se deslocam em direção à planícies fluviais que, a partir desse aporte das dunas e por meio de suas correntes, transportam estes sedimentos até as regiões praianas, como acontece no rio Pacoti, no trecho próximo a sua foz.

Conforme citado acima, as dunas são depósitos de sedimentos arenosos em constante movimento e, por conseguinte, não permitem o desenvolvimento de processos de pedogênese, ou seja, de formação de solos, por isso comumente são relacionadas à ausência de vegetação. Vale lembrar que o desenvolvimento pedológico é condição básica para a instalação e desenvolvimento da flora, sobretudo, de maior porte. Contudo, existe um determinado grupo de plantas que apresenta uma baixa exigência nutricional para sobreviver e consegue habitar estes locais. Este grupo é denominado de plantas pioneiras psamófilas.

Conceitualmente, plantas psamófilas são aquelas que sobrevivem, preferencialmente em ambientes arenosos. O termo "pioneiro" refere-se mais precisamente à sucessão ecológica, visto que este é o primeiro grupo de plantas a surgir no ambiente praial, devido a sua baixa exigência nutricional. As plantas pioneiras, por sua vez, fornecem matéria orgânica ao seu substrato e este começa a se transformar em solo, atendendo as necessidades nutricionais de outras plantas mais exigentes no processo de fixação das dunas.

Por outro lado, a fauna deste ambiente de dunas moveis é rara e pouco diversificada, sobretudo quando situada mais longe de algum tipo de fonte de água (curso d'água natural - riacho, córrego, rio; lagoa etc.). É representada principalmente por crustáceos do grupo dos decápodes (siris) e alguns anelídeos poliquetas. Dentre os vertebrados, tem-se pequenos répteis (lagartos).

Além desses relevantes aspectos supracitados, o ambiente de dunas compõe, por vezes, cenários de beleza singulares, utilizados muitas vezes pelas prefeituras municipais, como a principal porta de entrada para o turismo de estados como o Ceará.

A pressão sobre o meio ambiente e, principalmente, a ocupação de áreas costeiras incitou a ação de mecanismos legais, a fim de proteger e organizar a ocupação da zona costeira dentre elas as áreas de dunas que cobrem grandes porções da costa brasileira, incluindo o Estado do Ceará.

Apesar dessa importância, as restrições legais para sua ocupação apresentam hiatos ao longo das últimas décadas, sobremaneira, em âmbito federal. Exemplo atual disso é o fato das dunas móveis não estarem contempladas como áreas de preservação permanente (APPs) na recentemente promulgada (e ainda bastante discutida) (BRASIL, 2012a).

De antemão, conforme aponta Catelani e Batista (2007), vale frisar que as Áreas de Preservação Permanente (APPs) foram criadas para proteger o ambiente natural, o que significa que não são áreas apropriadas para alteração de uso da terra. O regime de proteção das APP é bastante rígido: a regra é a intocabilidade, admitida excepcionalmente a supressão da vegetação apenas nos casos de utilidade pública ou interesse social legalmente previstos (ARAÚJO, 2002).

\section{O CÓDIGO FLORESTAL DE 1934}

$\mathrm{Na}$ tentativa de ordenar os diversos interesses envolvidos na utilização das terras, o Estado brasileiro vem regulamentando o uso e ocupação do solo por meio de promulgação de leis, decretos e resoluções, desde a década de 1930 (MARCHIORO et al, 2010).

No ano de 1934, em meio à forte expansão cafeeira ocorrente no Brasil, surgiu o primeiro Código Florestal. Principalmente no Sudeste, empurradas e suprimidas pelas frentes de plantações, as florestas ficavam cada vez mais distantes das cidades, dificultando e encarecendo, por conseguinte, o transporte de lenha. Desta forma, a legislação visava impedir os efeitos sociais e políticos negativos causados pelo aumento do preço, ou pior, pela falta da lenha, garantindo, dessa forma, a popularidade do novo regime, instaurado com a Revolução de 1930 (BRASIL, 2012b).

Desta forma, foi o governo Getúlio Vargas que, em 1934, criou o Código Florestal, junto com os códigos de Água, Minas, Caça e Pesca e a primeira Conferência Brasileira de Proteção à Natureza, todos eles, formando uma tentativa do Estado de ordenar o uso dos recursos naturais em um país que passava por mudanças importantes (BRASIL, 2012b). 
Dunas móveis: Áreas de Preservação Permanente?

Mônica Virna Aguiar Pinheiro, Marcelo Martins Moura-Fé, Eduardo Marcelo Negreiros Freitas, Anatarino Torres Costa,

Aline Carla Sousa Aguiar, Enio Tarsom Paiva Sombra

A solução do Código Florestal de 1934 (Decreto $\mathrm{n}^{\circ} 23.793 / 1934$ ) foi obrigar os proprietários de terras a manterem $25 \%$ da área de seus imóveis com a cobertura de mata original. Era a chamada "quarta parte". Porém, não havia qualquer orientação sobre em qual parte das terras (margens dos rios ou outras) a floresta deveria ser preservada, o que sabemos, faz toda a diferença no tocante á preservação ambiental.

A lei até incentivava a retirada total das matas nativas desde que pelo menos os $25 \%$ de reserva de lenha fossem replantados. Nesse sentido, não importava a espécie e nem a variedade de árvores, mas apenas a garantia de produção de madeira para lenha e carvão.

Segundo Brasil (2012b), apesar disso, a lei de 1934 também demonstrava viés de preservação ambiental, ao criar a figura das florestas protetoras, para garantir a qualidade ambiental de rios e lagos e a estabilidade de áreas de risco (encostas íngremes e dunas). Mais tarde, esse conceito deu origem às áreas de preservação permanente (APPs), também localizadas em imóveis rurais.

Vale informar que essa lei tratava as dunas em seu $\operatorname{art} 4^{\circ}$, da seguinte forma: "Art. $4^{\circ}$ Serão consideradas florestas protectoras as que, por sua localização, servirem conjuncta ou separadamente para qualquer dos fins seguintes: (...) c) fixar dunas."

Como pode se verificar, a lei tratava da vegetação que recobre e fixa as dunas, incluindo aí, somente as dunas fixas.

\section{O CÓDIGO FLORESTAL DO SÉCULO XX: A LEI No 4.771/1965.}

Com o advento dos novos combustíveis e fontes de energia, como as hidrelétricas, a lenha foi deixando progressivamente de ter importância econômica. Inversamente, crescia a consciência do papel do meio ambiente e das florestas. Assim, em 1960, o Legislativo se mobilizou para alterar a lei de 1934, e a função das florestas em terrenos privados (BRASIL 2012c).

Em 15 de setembro de 1965, o então presidente Humberto de Alencar Castelo Branco, cearense de Fortaleza, sancionava a Lei Federal n ${ }^{\circ} 4.771$ (BRASIL, 1965). O "novo" Código Florestal estabelecia 50\% de reserva legal na Amazônia e 20\% no restante do país (art. 16) e definia a localização das áreas de preservação perma- nente (art. 2 e 3). Além disso, essa lei também definiu as áreas de preservação permanente (APPs) que deveriam ser obrigatoriamente mantidas, no campo ou nas cidades.

As APPs, ou áreas de preservação permanente, foram definidas em margens de cursos d'água, lagos, lagoas e reservatórios artificiais, topos de morros e encostas com declividade elevada, cobertas ou não por vegetação nativa, com a função ambiental de preservar os recursos hídricos, a paisagem, a estabilidade geológica, a biodiversidade, o fluxo gênico de fauna e flora, e de proteger o solo e assegurar o bem estar da população humana (BRASIL, 1965). São consideradas áreas mais sensíveis e sofrem riscos de erosão do solo, enchentes e deslizamentos.

Assim como na sua lei antecessora, a lei federal n 4.771 de 1965 não apresenta as dunas móveis como APPs. Em seu art. $2^{\circ}$, que diz: "Consideram-se de preservação permanente, pelo só efeito desta Lei, as florestas e demais formas de vegetação natural situadas: (...) f) nas restingas, como fixadoras de dunas ou estabilizadoras de mangues."

Essa exclusão fica clara no art. $3^{\circ}$ da referida lei, que diz: "Consideram-se ainda, de preservação permanentes, quando assim declaradas por ato do Poder Público, as florestas e demais formas de vegetação natural destinadas: (...) b) a fixar as dunas".

Nesse sentido, as dunas móveis enquanto APPs só se verificam no contexto da legislação brasileira através das Resoluções do CONAMA.

\section{AS RESOLUÇÕES CONAMA}

O Conselho Nacional do Meio Ambiente - CONAMA é o órgão consultivo e deliberativo do Sistema Nacional do Meio Ambiente - SISNAMA e foi instituído pela Lei $n^{\circ}$ 6.938/81 (BRASIL, 1981), que dispõe sobre a Política Nacional do Meio Ambiente, regulamentada pelo Decreto 99.274/90 (MMA, 2012a).

O Conselho é um colegiado representativo de cinco setores, a saber: órgãos federais, estaduais e municipais, setor empresarial e sociedade civil, o qual reúne-se ordinariamente a cada 03 meses no Distrito Federal, podendo realizar Reuniões Extraordinárias fora do Distrito Federal, sempre que convocada pelo seu Presidente, por iniciativa própria ou a requerimento de pelo menos $2 / 3$ dos seus membros. 
Dunas móveis: Áreas de Preservação Permanente? Mônica Virna Aguiar Pinheiro, Marcelo Martins Moura-Fé, Eduardo Marcelo Negreiros Freitas, Anatarino Torres Costa, Aline Carla Sousa Aguiar, Enio Tarsom Paiva Sombra

Em 2002, mais precisamente em 20 de março, o CONAMA publica a Resolução CONAMA n ${ }^{\circ} 303$ (MMA, 2012b), que dispõe sobre parâmetros, definições e limites de Áreas de Preservação Permanente, trazendo de forma pioneira, as dunas móveis enquanto APPs. Exemplos dessa atenção e interesse são apresentados nos considerandos acrescentados posteriormente pela Resolução CONAMA nº 341/2003 (MMA, 2012c), que dizem:

Considerando a função fundamental das dunas na dinâmica da zona costeira, no controle dos processos erosivos e na formação e recarga de aqüiferos; (considerando acrescentado pela Resolução $\left.n^{\circ} 341 / 03\right)$;

(...)

Considerando a excepcional beleza cênica e paisagística das dunas, e a importância da manutenção dos seus atributos para o turismo sustentável; (considerando acrescentado pela Resolução $\left.n^{\circ} 341 / 2003\right)$;

(...)

Essa resolução traz ainda em seu art. $1^{\circ}$, que diz:

Art. $1{ }^{\circ}$ Constitui objeto da presente Resolução o estabelecimento de parâmetros, defi nições e limites referentes às Áreas de Preservação Permanente.

$X$ - duna: unidade geomorfológica de constituição predominante arenosa, com aparência de cômoro ou colina, produzida pela ação dos ventos, situada no litoral ou no interior do continente, podendo estar recoberta, ou não, por vegetação; Grifo nosso.

Por fim, estabelecendo as dunas móveis enquanto APPs, tem-se o art. $3^{\circ}$ da referida resolução, que diz: "Constitui Área de Preservação Permanente a área situada: (...) XI - em duna".

Com o estabelecimento das áreas de dunas móveis como áreas de preservação permanente, esse ambiente estaria legalmente protegido do uso e ocupação, pois, como afirma (ARAÚJO, 2002), o regime de proteção das APPs é bastante rígido: a regra é a da intocabilidade, admitida excepcionalmente apenas nos casos de utilidade pública ou interesse social legalmente previstos.

\section{A RELAÇÃO ENTRE A LEI FEDERAL E A RE- SOLUÇÃO CONAMA}

Desde então, o Novo (até então) Código Florestal (Lei no 4.771/1965 - BRASIL, 1965) em regime de complementaridade com a Resolução CONAMA ${ }^{\circ}$ 303/2002 determinavam o licenciamento sobre as APPs, entendendo as dunas móveis também como APPs.

Corroborando essa relação, o CONAMA editou, posteriormente, outra importante Resolução versando sobre as dunas móveis, que foi a Resolução CONAMA n ${ }^{\circ} 341 / 2003$ (BRASIL, 2012c), que dispõe sobre critérios para a caracterização de atividades ou empreendimentos turísticos sustentáveis como de interesse social para fins de ocupação de dunas originalmente desprovidas de vegetação, na Zona Costeira.

Apesar de abrir precedente por meio de diretrizes, condições e procedimentos para ocupação das dunas móveis, ou "dunas originalmente desprovidas de vegetação", a referida resolução mantinha as dunas móveis enquanto áreas de preservação permanente e assim, a restrição ao uso e ocupação desse ambiente.

Ainda se tratando das regulamentações via CONAMA, importante salientar que a Resolução CONAMA no 369/2006 (MMA, 2012d), conforme entendimento de diversos especialistas nessa seara do direito ambiental, derrogou a Resolução CONAMAn ${ }^{\circ}$ 341/2003 (MMA, 2012c), no tocante ao uso e ocupação de dunas. As consequências deste fato atingiram, inclusive, os empreendimentos com licenciamentos já concluídos à época da entrada em vigor da Resolução $n^{\circ}$ 369/2006.

Nesse sentido, de acordo com o artigo $2^{\circ}$ da mencionada resolução, é vedado que o órgão ambiental competente autorize a intervenção ou supressão de vegetação em APP no caso de atividades de pesquisa e extração de substâncias minerais, quando se tratar das dunas, assim definidas no art. $3^{\circ}$, XI, da Resolução CONAMA n ${ }^{\circ}$ 369/2006 (MMA, 2012d).

\section{A TUTELA CONSTITUCIONAL DO MEIO AMBIENTE E O POSSÍVEL E IMPORTANTE PAPEL DA MUNICIPALIDADE}

Até o início dos anos oitenta pode-se dizer que não havia uma legislação de proteção do Meio Ambiente no Brasil. O que havia, até então, eram escassas 
Dunas móveis: Áreas de Preservação Permanente?

Mônica Virna Aguiar Pinheiro, Marcelo Martins Moura-Fé, Eduardo Marcelo Negreiros Freitas, Anatarino Torres Costa,

Aline Carla Sousa Aguiar, Enio Tarsom Paiva Sombra

regulamentações com ordenamentos relativos à água e florestas, no entanto, mais com o objetivo de proteção econômica do que a específica proteção ambiental. Só para se ter idéia da escassez de legislação, as Constituições anteriores à de 1988 não aplicavam regras específicas sobre o Meio Ambiente (GOMES, 2008).

Uma ressalva citada por Gomes (2008), no entanto, é sobre a Constituição Federal de 1946, a única que fez menção sobre o direito ambiental ao estabelecer que a competência legislar sobre a proteção da água, das florestas, da caça e pesca competia à União.

A Constituição Federal Brasileira de 1988 (BRASIL, 1988), além de consagrar a preservação ambiental, definiu as competências dos entes federativos, de forma que descentralizou a proteção do meio ambiente. A União, Estados, Municípios e Distrito Federal passaram a ter ampla competência para legislarem em matéria ambiental.

A Constituição, em seu artigo 225, fixou os princípios gerais em relação ao Meio Ambiente e estabeleceu, no terceiro parágrafo, que nas condutas e nas atividades lesivas ao Meio Ambiente, os infratores, pessoas físicas ou jurídicas, ficariam sujeitos às sanções penais e administrativas e, além disso, independentemente da obrigação de reparar o dano causado (GOMES, 2008).

A idéia, segundo Gomes (2008), era estabelecer uma nova forma de agir e pensar e, consequentemente, educar. Na Constituição Federal de 1988, o direito a um meio ambiente sadio foi consagrado como um direito fundamental do homem, uma vez que o Meio Ambiente é considerado como um bem de uso comum do povo e, assim, essencial para a qualidade de vida.

A Constituição Federal também estabeleceu medidas e providências cabíveis tanto à União como aos Estados e municípios e que se destinam a assegurar a efetividade do Meio Ambiente equilibrado, presentes nos incisos de I a VIII do art. 225. A inserção de um capítulo tratando, especificamente, das questões ambientais na Constituição Federal é reflexo, já neste tempo, de uma consciência de preservação, em decorrência dos problemas ambientais emergentes e das pressões populares que se iniciaram a partir da década de 1970, com a organização da sociedade civil brasileira (GOMES, 2008).
Por outro lado, coforme se extrai da leitura do art. 24 da nossa Carta Magna, a competência para criação de leis ambientais no nosso ordenamento jurídico é concorrente, assim chamada aquela competência na qual a União edita normas gerais, enquanto os estados-membros e o Distrito Federal suplementam essas normas. Apesar do citado artigo não fazer menção a competência legislativa dos Municípios, essa vem garantida no artigo 30, I e II da CF/88, o qual aduz que compete aos Municípios legislar sobre assuntos de interesse local, bem como suplementar a legislação federal e estadual no que couber.

Aos estados-membros foi dada ainda a competência de legislar plenamente para atender as suas particularidades quando a União não editar norma geral.

Após a Constituição Federal de 1988, verifica-se que os Municípios adquiriram uma especial importância na nossa Federação, sendo entes autônomos. Dessa forma, podem e devem agir em prol da proteção do meio ambiente, sendo, pois, a atuação de tais entes, fundamental para a proteção do patrimônio ambiental local. A Resolução CONAMA no 237/1997 (MMA, 2012e) corrobora coma ênfase da importância municipal no tocante à legislatura ambiental. Nesse sentido, podem e devem legislar em caso de omissão de lei federal e quando houver "interesse local".

Destaque-se que, ainda que havendo normas federais ou estaduais sobre o mesmo assunto, a legislação municipal pode ser aplicada quando for mais protecionista em favor do meio ambiente. Conforme a Lei da Política Nacional do Meio Ambiente (Lei federal n ${ }^{\circ} 6.938$, de 31 de agosto de 1981 - BRASIL, 1981).

Destarte, a utilização de tal competência municipal é pode ser extremamente importante para o caso em tela, uma vez que tais entes federativos podem e na presente questão, faz-se necessário, em face da importância local dos campos de dunas existentes em seus limites territoriais, que legislem mais restritamente, ou seja, de forma mais protecionista mesmo diante de legislação em âmbitos federal e estadual que, porventura, não inclua as dunas móveis como APPs. 
Dunas móveis: Áreas de Preservação Permanente?

\section{O NOVO CÓDIGO FLORESTAL DO SÉCULO} XXI E SUAS ALTERAÇÕES

Apesar de ser uma lei importante para a sociedade, houve uma imensa pressão de parte do setor agropecuário para a modificação da lei $n^{\circ}$ 4.771/1965. A razão da insatisfação é que, após muitas décadas de esquecimento, ela começou a ser aplicada de forma mais efetiva.

Em 1998, a Lei de Crimes Ambientais trouxe penas mais duras para quem desobedecesse a legislação ambiental. A fiscalização no campo aumentou e o Ministério Público passou a agir com mais vigor em suas denúncias. Segundo Souza et al. (2012), o Brasil vive uma nova realidade jurídica, na qual os atos administrativos envolvidos com a questão ambiental são constantemente levados ao controle do Poder Judiciário.

Até o momento da sua promulgação, cerca de 36 projetos de lei tentaram derrubar o Código Florestal. Todavia, apesar das pressões e das inúmeras discussões, em maio de 2012, foi sancionada a Lei federal n ${ }^{\circ}$ 12.651/2012, que "dispõe sobre a proteção da vegetação nativa; altera as Leis ${ }^{\text {os }} 6.938$, de 31 de agosto de 1981, 9.393, de 19 de dezembro de 1996, e 11.428, de 22 de dezembro de 2006; revoga as Leis $\mathrm{n}^{\text {os }} 4.771$, de 15 de setembro de 1965, e 7.754, de 14 de abril de 1989, e a Medida Provisória no 2.166-67, de 24 de agosto de 2001; e dá outras providências".

Em seu art. $4^{\circ}$, que traz a relação de áreas de preservação permanente, o novo código florestal, assim como os códigos florestais que o antecederam, não cita as dunas móveis. A partir disso, algumas questões podem ser lançadas, tais como:

Se a Resolução CONAMA nº 303/2022 era válida para tratar de forma conjunta com a Lei $\mathrm{n}^{\circ}$ $4.771 / 1965$, por que não seria válido agora? Por que no $1^{\circ}$ caso, a lei era anterior à edição da resolução? $\mathrm{Ou}$ isso não procederia?

Se a nova lei federal $n^{\circ} 12.651 / 2012$ não expressa a revogação da resolução CONAMA $n^{\circ}$ 303-2002, tampouco as disposições em contrário, como geralmente ocorre com uma lei, a Resolução CONAMA n ${ }^{\circ}$ 303-2002 não seria válida?

Em meio à essas questões, em outubro de 2012, foi sancionada a lei $n^{\circ} 12.727$ (BRASIL, 2012d), que dispõe sobre alterações no atual código florestal, dentre as quais, acerca do art. $4^{\circ} \mathrm{e}$ das áreas de preservação permanente.

Todavia, as alterações se dão no tocante à redação do art. $4^{\circ}$, sem maiores alterações, enfim, com a permanência da ausência das dunas móveis enquanto áreas de preservação permanente.

\section{O ENTENDIMENTO CONSTITUCIONAL E LEGAL SOBRE O TEMA}

O ordenamento jurídico brasileiro divide as normas em regras e princípios. Estes são considerados como mandamentos de otimização, já que servem de embasamento para a criação das normas jurídicas.

As regras estabelecem os parâmetros e possuem aspecto objetivo. A disposição expressa permite que os aplicadores da lei façam a subsunção da regra ao caso concreto e estabeleçam a validade daquela relação. Assim, as normas jurídicas possuem validade, vigência e eficácia.

A dinâmica das relações jurídicas impõe as mudanças legislativas, o que torna necessária a constante atualização das leis. Dessa forma, a Lei de Introdução às normas do Direito Brasileiro (Decreto-lei 4.657/1942) esclarece em seu artigo $2^{\circ}$ que a lei terá vigor até que outra a modifique ou revogue.

Segundo o parágrafo primeiro do referido dispositivo: "A lei posterior revoga a anterior quando expressamente o declare, quando seja com ela incompatível ou quando regule inteiramente a matéria de que tratava a lei anterior". Ademais, na elaboração de qualquer lei, o legislador deve seguir os ditames da Lei Complementar $n^{\circ}$ 95, de 26 de fevereiro de 1998.

Segundo Bobbio (2003), uma norma é válida quando são realizadas três operações:

1) averiguar se a autoridade de quem ela emanou tinha o poder legítimo para emanar normas jurídicas, isto é, normas vinculantes naquele determinado ordenamento jurídico (esta investigação conduz inevitavelmente a remontar até a norma fundamental, que é o fundamento de validade de todas as normas de um determinado sistema);

2) averiguar se não foi ab-rogada, já que uma norma pode ter sido válida, no sentido de que 
Dunas móveis: Áreas de Preservação Permanente?

Mônica Virna Aguiar Pinheiro, Marcelo Martins Moura-Fé, Eduardo Marcelo Negreiros Freitas, Anatarino Torres Costa,

Aline Carla Sousa Aguiar, Enio Tarsom Paiva Sombra

foi emanada de um poder autorizado para isto, mas não quer dizer que ainda o seja, o que acontece quando uma outra norma sucessiva no tempo a tenha expressamente ab-rogado ou tenha regulado a mesma matéria;

3) averiguar se não é incompativel com outras normas do sistema (o que também se chama ab-rogação implícita), particularmente com uma norma hierarquicamente superior (uma lei constitucional é superior a uma lei ordinária em uma Constituição rígida) ou com uma norma posterior, visto que em todo ordenamento jurídico vigora o princípio de que duas normas incompativeis não podem ser ambas válidas.

Não se pode esquecer dos critérios utilizados quando ocorrem antinomias aparentes. Para a solução dos conflitos existem os critérios cronológico, hierárquico e da especialidade.

O critério cronológico estabelece que uma norma posterior prevalece sobre a norma anterior. Por sua vez, o critério hierárquico dispõe que a norma hierarquicamente superior prevalece sobre a inferior. Por fim, o critério da especialidade estabelece que a norma especial predomina sobre a geral.

O surgimento da Lei 12.651/2012 trouxe várias controvérsias quanto ao aspecto de validade de outras normas jurídicas.

Apesar de o novo Código Florestal ter expressamente asseverado no artigo 83 que se revogam as Leis $\mathrm{n}^{\text {os }} 4.771$, de 15 de setembro de 1965 , e 7.754 , de 14 de abril de 1989, e suas alterações posteriores, e a Medida Provisória ${ }^{\circ}$ 2.166-67, de 24 de agosto de 2001, percebe-se que alguns assuntos não foram abordados de maneira ideal na nova lei, o que motivará diversos questionamentos.

Para exemplificar, citam-se com mais ênfase as dunas móveis, as quais possuíam regulamentação expressa, na Resolução CONAMA no 303/2002, como áreas de preservação permanente, conforme apresentamos acima.

A referida resolução regulamentava 0 art. $2^{\circ}$ da Lei $\mathrm{n}^{\circ} 4.771$, de 15 de setembro de 1965 . Como a lei foi revogada expressamente, por conseguinte, a resolução perde sua validade, eis que a norma que serviu de parâmetro para sua criação já não mais vigora no ordenamento jurídico.
Destaque-se que existem questionamentos sobre o papel do CONAMA na edição de resoluções que extrapolam o poder regulamentar estipulado.

Para exemplificar, cita-se Machado (2011):

Na Resolução CONAMA no 302/2002 foi estatuida área marginal ao redor do reservatório artificial, com diversas medidas (art. $\left.3^{\circ}\right)$; assim como na Resolução $n^{\circ}$ 303/2002 foram estabelecidos os entornos dos lagos e lagoas naturais, veredas e de alguns outros elementos geomorfológicos, sendo que no Código Florestal não consta a indicação dessas medidas. O CONAMA agiu de boa-fé, mas nestas partes em que foram ultrapassados os limites indicados em lei as resoluções não têm força obrigatória.

(...)

O CONAMA tem função social e ambiental indispensável. Mas esse Conselho não tem função legislativa, e nenhuma lei poderia conceder-lhe essa função. Estamos diante de uma patologia jurídica, que precisa ser sanada, pois caso contrário o mal poderia alastrar-se e teríamos o Conselho Monetário Nacional criando impostos e o Conselho Nacional de Política Criminal e Penitenciária definindo os crimes. É fundamental a proteção das APPS, mas dentro do Estado de Direito.

Apesar desse posicionamento, o CONAMA vem cumprindo seu mister com o objetivo de evitar que algumas áreas sejam devastadas, em que pese não existir lei específica.

Não se pode esquecer de que existe o Projeto de Lei $n^{\circ} 1.197 / 2003$, que considera todas as dunas como espaços territoriais especialmente protegidos, contudo se encontra estagnado desde 15 de junho de 2004, quando o relator proferiu parecer favorável. O referido ato legislativo faz menção ao antigo Código Florestal. Como este foi revogado, o projeto deve ser retificado ou deve surgir novo projeto de lei condicionado à Lei $12.651 / 2012$. 
Dunas móveis: Áreas de Preservação Permanente? Mônica Virna Aguiar Pinheiro, Marcelo Martins Moura-Fé, Eduardo Marcelo Negreiros Freitas, Anatarino Torres Costa, Aline Carla Sousa Aguiar, Enio Tarsom Paiva Sombra

Segundo o artigo 24, inciso VI, da Constituição Federal, existe competência concorrente da União, dos Estados e do Distrito Federal para legislar sobre florestas, conservação da natureza, proteção ao meio ambiente, dentre outros. A União estabelece as diretrizes gerais, existindo a competência suplementar dos Estados. O parágrafo terceiro do referido artigo dispõe que os Estados exercerão a competência plena caso não exista lei federal sobre as normas gerais.

Com o novo Código Florestal o legislador perdeu grande oportunidade de traçar normas gerais sobre as dunas. Apesar disso, Estados como Bahia, Rio de Janeiro, Espírito Santo, Maranhão e Sergipe consideram as dunas como áreas de preservação permanente em suas respectivas constituições. Percebe-se que os referidos Estados exerceram a competência plena e regulamentaram a preservação das dunas.

Enfim, como o novo Código Florestal revogou expressamente a Lei $n^{\circ} 4771 / 1965$, por conseguinte, pode-se considerar que ocorreu a revogação tácita da Resolução CONAMA n $303 / 2002$, não podendo esta norma prevalecer, pois é hierarquicamente inferior à lei, apesar de não contrariá-la. Ademais, para alguns doutrinadores, a Resolução no 303/2002 do CONAMA não possui força obrigatória, motivo pelo qual a validade e a eficácia da referida regra continuam sendo questionadas.

\section{CONCLUSÕES: DUNAS MÓVEIS, ÁREAS DE PRESERVAÇÃO PERMANENTE DE FATO E DE DIREITO}

Entendendo que a Lei ${ }^{\circ} 12.651 / 2012$, que institui o Novo Código Florestal, revogou tacitamente a Resolução CONAMA n ${ }^{\circ}$ 303/2002 e, por conseguinte, retirou as dunas móveis da relação de APPs, como solução, caberia ao CONAMA editar nova resolução para regulamentar o artigo $4^{\circ}$ da Lei 12651/2012.

Outra alternativa que poderia ser adotada seria a promulgação de lei estadual, ou mesmo, municipal, incluindo as dunas móveis como APPs. Isso seria possível, tendo em vista que a Lei $n^{\circ} 6.936 / 1981$, que dispõe sobre a Política Nacional do Meio Ambiente, em seu art. $4^{\circ}$, parágrafo II, afirma que, a Política Nacional do Meio Ambiente visará: "à definição de áreas prioritárias de ação governamental relativa à qualidade e ao equilíbrio ecológico, atendendo aos interesses da União, dos Estados, do Distrito Federal, dos Territórios e dos Municípios".

Ademais, considerando as próprias características de áreas de preservação permanente, apresentadas no art. $3^{\circ}$ da Lei 12.651/2012 que diz:

\section{(...) II - Área de Preservação Permanente-APP: área protegida, coberta ou não por vegetação nativa, com a função ambiental de preservar os recursos hidricos, a paisagem, a estabilidade geológica e a biodiversidade, facilitar o fluxo gênico de fauna e flora, proteger o solo e as- segurar o bem-estar das populações humanas.}

As dunas móveis enquadram-se claramente como áreas de preservação permanente de fato, devendo, portanto, receberem a proteção adequada.

Diante disso, espera-se uma rápida atuação do CONAMA na edição de nova resolução, sob pena de surgirem muitos questionamentos acerca das regras que estão sem regulamentação, não se podendo esquecer, entretanto, do ato jurídico perfeito e do direito adquirido.

Outrossim, considerando que a Constituição do Estado do Ceará não dispõe sobre as dunas como áreas de preservação permanente, deve-se buscar uma rápida mobilização para a alteração da norma indicada, pois, enquanto isso, esta lacuna legal associada à fiscalização ineficiente do órgão ambiental competente, ao longo dos anos vem resultando na extinção e descaracterização morfológica das dunas, importantes feições para o equilíbrio ambiental, ao longo do litoral cearense. A continuidade deste quadro pode resultar mais ainda na diminuição das áreas de campo de dunas móveis e em mudanças de dinâmica natural destes relevos em nossa região, bem como, na zona costeira e litorânea como um todo.

Assim, vale ainda ressaltar a importância da preservação das áreas de dunas móveis como forma de equilíbrio da natureza (área de recarga de aqüífero, dinâmica sedimentar da zona costeira, além de seus aspectos estéticos que atraem o segmento turístico). por essa razão se faz necessário uma política de uso adequado para essas áreas a fim de preservá-la com uso sustentável com base em leis e diretrizes sólidas e coerentes. 
Dunas móveis: Áreas de Preservação Permanente?

Mônica Virna Aguiar Pinheiro, Marcelo Martins Moura-Fé, Eduardo Marcelo Negreiros Freitas, Anatarino Torres Costa,

Aline Carla Sousa Aguiar, Enio Tarsom Paiva Sombra

\section{AGRADECIMENTOS}

$\mathrm{O}$ artigo resulta de pesquisa financiada pela Fundação Cearense de Apoio ao Desenvolvimento Científico e Tecnológico - FUNCAP, Ceará, Brasil.

\section{REFERÊNCIAS}

ARAÚJO, S. M. V. G. As Áreas de Preservação Permanente e a Questão Urbana. Brasília: Edições Câmara, 2002.

BRASIL. Decreto-lei $n^{\circ} 4.771$, de 15 de setembro de 1965. Institui o Novo Código Florestal Brasileiro e dá outras providências. Diário Oficial (da) República Federativa do Brasil. Poder Executivo. Brasília, DF, 1965.

BRASIL. Lei Federal $n^{\circ}$ 6.938, de 31 de agosto de 1981. Dispõe sobre a Política Nacional do Meio Ambiente. Diário Oficial (da) República Federativa do Brasil. Poder Executivo. Brasília, DF, 1981.

BRASIL. Constituição da Republica Federativa do Brasil. Brasília: Editora Senado, 1988.

BRASIL. Lei Federal n 12.651, 25 de maio de 2012. Dispõe sobre o Código Florestal. Diário Oficial (da) República Federativa do Brasil. Poder Executivo. Brasília, DF, 2012a.

BRASIL. Código Florestal de 1934. Jornal do Senado Federal. Disponível em: <http://www.senado. gov.br/NOTICIAS/JORNAL/EMDISCUSSAO/ codigo-florestal/senado-oferece-um-projeto-equilibrado-para-o-novo-codigo-florestal-brasileiro/ codigo-florestal-de-1934.aspx>, acesso em: 28 jul. 2012b.

BRASIL. Código Florestal de 1965. Jornal do Senado Federal. Disponível em: <http://www.senado. gov.br/NOTICIAS/JORNAL/EMDISCUSSAO/ codigo-florestal/senado-oferece-um-projeto-equilibrado-para-o-novo-codigo-florestal-brasileiro/ codigo-florestal-de-1965.aspx $>$, acesso em: 28 de jul. 2012c.
BRASIL. Lei Federal no 12.727, de 17 de outubro de 2012. Dispõe sobre alterações no Código Florestal. Poder Executivo. Brasília, DF, 2012d.

BOBBIO, N. Teoria da norma jurídica. 2 ed. Bauru: Edipro, 2003.

CATELANI, C. S. e BATISTA, G. T. Mapeamento das Áreas de Preservação Permanente (APP) do Município de Santo Antônio do Pinhal, SP: um subsídio à preservação ambiental. Revista Ambiente e Água, v. 2, n. 1, 2007.

GOMES, A. Legislação Ambiental e Direito: um Olhar sobre o Artigo 225 da Constituição Federativa do Brasil. Revista Científica Eletrônica de Administração, n. 14, p.01-11, 2008.

MACHADO. P. A. L. Direito Ambiental Brasileiro. 19 ed. São Paulo: Malheiros Editores, 2011.

MARCHIORO, E.; FERNANDES, N. F.; MACEDO, J. R.; BHERING, S. B. e GONÇALVEZ, A. O. Aplicação do Código Florestal Brasileiro como Subsídio para o Planejamento Ambiental: um Estudo de Caso na Região Noroeste do Estado do Rio de Janeiro. Sociedade e Natureza. Uberlândia, n. 22 (1), p. 11-21, 2010.

MOURA-FÉ, M. M. Evolução Geomorfológica do Sitio Natural de Fortaleza, Ceará. Dissertação (Mestrado em Geografia). Universidade Federal do Ceará, Fortaleza, 2008.

MMA. Ministério do Meio Ambiente / CONAMA. Conselho Nacional do Meio Ambiente. Resoluções do CONAMA: resoluções vigentes publicadas entre setembro de 1984 e janeiro de 2012. Brasília: MMA, 2012a. p. 09-14.

MMA. Ministério do Meio Ambiente / CONAMA. Resoluções do CONAMA: resoluções vigentes publicadas entre setembro de 1984 e janeiro de 2012. Brasília: MMA, 2012b. p. 73-75. 
MMA. Ministério do Meio Ambiente / CONAMA. Resoluções do CONAMA: resoluções vigentes publicadas entre setembro de 1984 e janeiro de 2012. Brasília: MMA, 2012c. p. 76-77.

MMA. Ministério do Meio Ambiente / CONAMA. Resoluções do CONAMA: resoluções vigentes publicadas entre setembro de 1984 e janeiro de 2012. Brasília: MMA, 2012d. p. 78-85.

MMA. Ministério do Meio Ambiente / CONAMA. Resoluções do CONAMA: resoluções vigentes publicadas entre setembro de 1984 e janeiro de 2012. Brasília: MMA, 2012e. p. 930-938.

PINHEIRO, M. V. A. Evolução Geoambiental e Geohistórica das Dunas Costeiras de Fortaleza, Ceará. Dissertação (Mestrado em Geografia). Universidade Federal do Ceará, 2009. Fortaleza, 2009.

SOUZA, A. G.; BORGES, L. A. e REZENDA, J. L. P. Controle Judicial do Ato Administrativo Ambiental. Holos Environment, v. 12, n. 1. p.1-11, 2012.

TSOAR, H; ARENS, S.M. Mobilização e Estabilização de Dunas em Climas Úmidos e Secos. Revista Mercator. Fortaleza, n. 5, p.131-144, 2003. 